Paper ID: 38791

Interface reactions and control of diffusion at the interface between SiC fibres and layer of deposited Fe-9Cr base alloy

S. Levchuk, S. Lindig, A. Brendel*, H. Bolt

*Corresponding author:

Annegret Brendel

Max-Planck-Institut für Plasmaphysik, EURATOM Association

Boltzmannstr. 2, 85748 Garching, Germany

Tel. $+490893299-2544$

Fax +49 089 3299-96-2544

Annegret.Brendel@ipp.mpg.de 


\title{
Interface reactions and control of diffusion at the interface between SiC fibres and layer of deposited Fe-9Cr base alloy
}

\author{
S. Levchuk, S. Lindig, A. Brendel, H. Bolt \\ Max-Planck-Institut für Plasmaphysik, EURATOM Association, Garching, Germany
}

\begin{abstract}
The ferromagnetic 9Cr steel EUROFER 97 is considered as a structural material for the first wall of future fusion reactors. To solve a problem of limitation of the maximum operation temperature of $550^{\circ} \mathrm{C}$ for EUROFER 97, a new metal matrix composite $\mathrm{SiC} /$ EUROFER 97 is proposed. To create a thermally stable interface between the $\mathrm{SiC}$ fibres and the steel matrix, the following interlayers were tested as a diffusion barrier: $\mathrm{Cr}, \mathrm{Re}, \mathrm{W}$ and $\mathrm{Re} / \mathrm{W}$. Samples with these interlayers were investigated before and after annealing at $750^{\circ} \mathrm{C}$ which is supposed to be the operation temperature of the composite material. To simplify examination of the coatings using available analysis methods (SEM, IBA and XRD), the fibre / steel system was approximated by planar samples with identical layer structure. The experiments with both $\mathrm{SiC}$ fibres and planar substrates revealed $\mathrm{W}$ to be an efficient diffusion barrier.
\end{abstract}

Keyword codes: C0100, C0900, D0300, I0200, S1000 


\title{
Interface reactions and control of diffusion at the interface between SiC fibres and layer of deposited Fe-9Cr base alloy
}

\author{
S. Levchuk, S. Lindig, A. Brendel, H. Bolt
}

\section{Introduction}

Due to importance of the low long-term activation property of fusion reactor components, the development of candidate materials with chemical composition based on low and reduced activation elements (Fe, Cr, V, Ti, Si, C, W and Ta) was of special interest in the past 15 years [1 - 3]. The operation temperature for EUROFER 97, one of these candidates, is limited to $550^{\circ} \mathrm{C}$ due to loss of its creep strength at high temperatures. This disadvantage has been overcome by the development of Oxide Dispersion Strengthened (ODS) variants of this steel. The EUROFER 97 steel strengthened with $\mathrm{Y}_{2} \mathrm{O}_{3}$ particles $(0.3-$ 1 wt.\%) allows an increase in the operation temperature by about $100^{\circ} \mathrm{C}$ [2 - 5]. An alternative might be material reinforcement with SiC fibres (SCS6, Specialty Material) resulting in a new composite material SiC-EUROFER 97 [6]. The SiC fibres can significantly improve the mechanical properties, especially creep, of the steel matrix over a wide temperature range. Furthermore, SCS6 fibres do not worsen the radiological behaviour of EUROFER 97, since Si and $\mathrm{C}$ are low activation materials. The operation temperature of the composite is expected to be about $750^{\circ} \mathrm{C}$.

Processing of the composite material SiC-EUROFER 97 consists of three steps. During the initial stage the SCS6 fibres are coated with a fine-structured Fe-9Cr base alloy interface layer on the fibre's surface by magnetron sputtering. Subsequently, a thick steel matrix layer with coarse structure is deposited by arc deposition using a EUROFER target. To form the final composite material, the coated fibres should be consolidated by hot isostatic pressing at $1000^{\circ} \mathrm{C}$ and $100 \mathrm{MPa}$.

Reactions occurring at the interface between the EUROFER 97 matrix and SiC fibres can lead to microstructural instability and thereby to degradation of the mechanical properties. For instance, it was observed in [7] that the tensile strength of the composite $\mathrm{SiC} /$ Ti alloy decreased by about 50\% when the thickness of the reaction zone between fibres and matrix reached a critical value of about $3 \mu \mathrm{m}$ due to annealing at $800^{\circ} \mathrm{C}$. Therefore, to suppress interdiffusion between fibres and matrix, an appropriate diffusion barrier should be applied in the form of a thin deposited coating on the fibre. For this purpose, Cr, Re and $\mathrm{W}$ 
interlayers and Re / W multilayer were investigated. Instead of fibres, planar substrates were examined for the investigation of diffusion interactions using the following techniques: Scanning Electron Microscopy (SEM), X-Ray Diffraction (XRD) and Ion Beam Analysis (IBA). To investigate the applicability of the results collected on planar samples, SCS6 fibres coated with $\mathrm{W}$ and steel layers were also investigated.

\section{Experimental details}

The commercially available SCS6 fibre (142 $\mu \mathrm{m}$ in diameter, Speciality Materials) consists of a central $\mathrm{C}$ monofilament, two concentric $\beta$-SiC zones grown in columnar structure and an outer coating of three layers containing free carbon with a total thickness of about $3 \mu \mathrm{m}$. The outer coating is SiC doped C with $\mathrm{C}$ content varying from 20 to $60 \%$ [8]. This outer coating is necessary for the formation of a diffusion barrier, to protect the fibre from the SiC decomposition caused by fibre-matrix interaction. To study the diffusion processes occurring between the SCS6 fibres and EUROFER matrix, the following substrates were investigated: pyrolytic graphite for modelling of $\mathrm{C}$ diffusion and $\mathrm{SiC}$ for modelling of interaction between the steel and SiC.

\section{Sample preparation}

A commercial magnetron sputter device "Discovery 18DC/RF" with 3 cathodes was used for deposition of the thin fine-structured coatings. The base pressure in the deposition chamber was $2 \cdot 10^{-5} \mathrm{~Pa}$. The coatings were deposited on pyrolytic graphite and SiC substrates and on the SCS6 fibres. Prior to deposition the substrates were rinsed with isopropanol in an ultrasonic bath and then etched in an Ar plasma. The applied DC power was varied from 100 to $200 \mathrm{~W}$ depending on the target material (EUROFER 97, Cr, Re, W), while Ar gas pressure of $0.36-0.45 \mathrm{~Pa}$ was applied. Thicknesses of the deposited coatings were in the range of 400 to $560 \mathrm{~nm}$.

For those samples containing an interlayer, deposition of steel was performed right after deposition of the interlayer had been finished, i.e. in the same chamber without breaking the vacuum. To investigate the behaviour of a coating and its reaction with a substrate material under temperatures comparable to the prospective working temperature, the samples with both planar substrates and fibres were annealed at $750^{\circ} \mathrm{C}$. The only exception was the SCS6 fibres coated with only steel (no interlayer) which were annealed at $600^{\circ} \mathrm{C}$. For all samples 
annealing was performed for 2 hours at the pressure in the vacuum chamber of about $3 \cdot 10^{-}$ ${ }^{4} \mathrm{~Pa}$.

\section{Characterisation}

To investigate the diffusion processes caused by annealing, the samples were analysed before and after annealing with different techniques:

- $\mathrm{SEM}$ - to investigate the surface and interface structure;

- $\quad \mathrm{IBA}$ - to measure the concentration depth profile of the coatings;

- $\mathrm{XRD}$ - to investigate the crystalline structure of the coating, including formation of new phases.

For IBA ${ }^{4} \mathrm{He}^{+}$ions were used with energies of $3.5-5 \mathrm{MeV}$ at an angle of incidence of $0^{\circ}$, an exit angle of $15^{\circ}$, and a scattering angle of $165^{\circ}$. Depth profiles were extracted from the backscattered energy distribution using simulation code SIMNRA 5.50 [9]. For XRD a diffractometer with a $\mathrm{Cu}$ anode working at the power settings of $40 \mathrm{kV}$ and $30 \mathrm{~mA}$ was utilized.

\section{Results and discussion}

\section{Steel layer on planar substrates}

The steel layer with thickness of $400 \mathrm{~nm}$ deposited on both $\mathrm{SiC}$ and graphite substrates possessed a fine structure and homogeneously covered the surface. Furthermore, the deposited layer showed a composition of the main elements very close to that of the EUROFER 97. Both $\mathrm{C}$ and $\mathrm{O}$ contents in the layer were found to be around the detection limit of 2 at. $\%$ or below.

The serious layer degradation, agglomeration caused by the surface diffusion was observed for the annealed sample with $\mathrm{SiC}$ substrate. Therefore, it was not possible to investigate the composition of the layer by XRD and IBA.

In contrast to $\mathrm{SiC}$, the layer on graphite revealed crack propagation after annealing, while the surface remained smooth. The crystalline structure of the annealed layer obtained by means of XRD showed the formation of a cementite $\left(\mathrm{Fe}_{3} \mathrm{C}\right)$ layer. The IBA depth profile revealed the presence of 27 at.\% of $\mathrm{C}(7.2 \mathrm{wt} . \%)$ in the steel layer, which is in a good agreement with formation of the cementite phase observed by XRD. This transformation led to the serious degradation of mechanical properties of the steel at the interface zone. 
To counteract the strong diffusion of $\mathrm{C}$ in steel, $\mathrm{Cr}, \mathrm{Re}, \mathrm{W}$ and $\mathrm{Re} / \mathrm{W}$ were tested as a diffusion barrier, since $\mathrm{C}$ has low diffusivity in $\mathrm{Cr}$ and $\mathrm{W}$ and low solubility in Re.

\section{Steel layer with diffusion barrier on planar substrates}

Both $\mathrm{SiC}$ and graphite substrates with $500 \mathrm{~nm} \mathrm{Cr}$ and $500 \mathrm{~nm}$ steel as a surface layer were investigated before and after annealing at $750^{\circ} \mathrm{C}$. For both substrates strong interdiffusion between $\mathrm{Cr}$ and steel layers resulted in complete intermixing of the layers due to influence of the $\mathrm{Cr}$ self-diffusion process, since there are 9 at.\% of $\mathrm{Cr}$ in pristine EUROFER alloy. XRD analysis of the annealed sample with $\mathrm{SiC}$ revealed the decomposition of $\mathrm{SiC}$ and, as a consequence, formation of $\mathrm{Fe}_{3} \mathrm{Si}$ silicide and $(\mathrm{Fe}, \mathrm{Cr})_{23} \mathrm{C}_{6},(\mathrm{Fe}, \mathrm{Cr})_{7} \mathrm{C}_{3}$ carbides took place. As to graphite, peaks of carbides, $\mathrm{Fe}_{3} \mathrm{C}$ and $\mathrm{Cr}_{7} \mathrm{C}_{3}$, appeared on the XRD pattern of the annealed sample. The presence of carbides observed by XRD was in a good agreement with a high $\mathrm{C}$ amount of 30 at.\% detected by IBA near the sample surface.

Re and steel, with each layer $500 \mathrm{~nm}$ thick, were investigated before and after annealing. Re-Fe precipitates in the form of white specks, caused by annealing and subsequent Re diffusion in steel, were observed by SEM. In contrast to $\mathrm{Cr}$, application of Re did not result in the decomposition of SiC, since the XRD pattern of the annealed sample did not reveal appearance of any new peak in comparison with the pattern of the pristine sample. Formation of a Re-Fe compound, namely $\mathrm{Fe}_{2} \mathrm{Re}_{3}$, was also evident from XRD measurements. In addition to $\mathrm{Fe}_{2} \mathrm{Re}_{3}$, the carbide $\mathrm{Cr}_{23} \mathrm{C}_{6}$ was detected for the sample with graphite due to diffusion of $\mathrm{C}$ from the substrate. The appearance of $\mathrm{Cr}$ carbide can be explained by the presence of $\mathrm{Cr}$ in EUROFER 97. Furthermore, Re does not form carbides, therefore a ternary phase Re-Fe-C is absent. Analysis of the IBA diffusion depth profile showed that the mean $\mathrm{C}$ and Re concentrations in steel were 8 and 10 at.\%, respectively. Thus, application of Re was more effective than $\mathrm{Cr}$ but it was still not sufficient to suppress the interdiffusion between the fibres and matrix.

$\mathrm{W}$ and steel, with each layer $500 \mathrm{~nm}$ thick, were investigated before and after annealing. Similar to the Re interlayer, the diffusion of $\mathrm{W}$ through the steel layer led to the formation of precipitates: $\mathrm{Fe}-\mathrm{W}$ in the case of $\mathrm{SiC}$ substrate and $\mathrm{Fe}-\mathrm{W}-\mathrm{C}$ in the case of graphite. In Fig. 1 SEM images of samples with SiC substrate before and after annealing are shown. The Fe-W precipitates are visible in Fig. $1 \mathrm{~b}$ as white specks. According to XRD measurements, SiC did not decompose at this temperature in the presence of $\mathrm{W}$ interlayer. The XRD pattern for the annealed sample with graphite substrate showed the formation of a $\mathrm{Fe}_{3} \mathrm{~W}_{3} \mathrm{C}$ phase. The appearance of $\mathrm{Fe}_{3} \mathrm{~W}_{3} \mathrm{C}$ can be explained by diffusion of $\mathrm{W}$ and $\mathrm{C}$ in steel and subsequent 
precipitate formation of $\mathrm{Fe}, \mathrm{W}$ and $\mathrm{C}$. The same reaction was also observed in [10] due to annealing at $700^{\circ} \mathrm{C}$. The IBA depth profile also revealed the $\mathrm{W}$ and $\mathrm{C}$ diffusion into steel. The $\mathrm{W}$ content in the steel layer of the annealed sample increased by 5.5 at.\% (EUROFER 97 consists of 0.25 at.\% of $\mathrm{W}$ ), while the $\mathrm{C}$ content in the steel was 3 at.\%. Therefore, the $\mathrm{W}$ diffusion barrier is more effective in suppressing of $\mathrm{C}$ diffusion into steel than $\mathrm{Re}$, since $\mathrm{Re}$ reacts intensively with $\mathrm{Fe}$ and it leads to deterioration of the suppression of $\mathrm{C}$ diffusion.

Taking into account the results of application of $\mathrm{Re}$ and $\mathrm{W}$ as diffusion barrier interlayers, a Re / W multilayer was prepared. It consisted of four interlayers of equal thicknesses of $140 \mathrm{~nm}, \mathrm{Re} / \mathrm{W} / \mathrm{Re} / \mathrm{W}$. Because of fast mixing of Re and Fe, W was chosen as an adjoining layer to the steel. This experiment was performed only with a graphite substrate since application of either $\mathrm{W}$ or Re did not lead to $\mathrm{SiC}$ decomposition. Graphite substrates covered by the $560 \mathrm{~nm}$ thick Re/W multilayer and $500 \mathrm{~nm}$ of steel were investigated before and after annealing. After annealing the surface of the sample remained smooth. The precipitate formation was observed, as in the cases of single W and Re layers. IBA depth profiles showed four clearly separated interlayers and the steel layer on the top for both pristine and annealed samples with only one exception: W from the W interlayer had partially diffused through the steel. The mean concentrations of additional $\mathrm{W}$ and $\mathrm{C}$ in the steel layer were found to be 4.6 at.\% and 2.5 at.\%, correspondingly. This is slightly lower than in the case of application of the single $\mathrm{W}$ layer.

For comparison of the investigated samples with and without an interlayer, the mean concentration of $\mathrm{C}$ in steel is presented as a diagram in Fig. 2.

\section{Steel layer with and without W diffusion barrier on the SCS6 fibre}

To investigate the applicability of the results acquired with planar samples, SCS6 fibres were coated with a $350 \mathrm{~nm}$ W diffusion barrier and a $350 \mathrm{~nm}$ steel surface layer. The W interlayer was chosen because of the simplicity of its deposition. The coated fibres with a W diffusion barrier were annealed at $750^{\circ} \mathrm{C}$ for 2 hours. The surface of the coated fibres remained intact and no cracks were found in the layers after annealing. Precipitate formation caused by the reaction between steel and W layers was also observed on the coated fibres. In Fig. 3 SEM images of the cross-section of the coated fibres after annealing are shown: in Fig. $3 a$ the fibre is only coated with the steel layer and in Fig. $3 b$ the fibre is coated with both the $\mathrm{W}$ and steel layers. To protect the annealed fibre from delamination of the coating during preparation of the cross-section, the fibre shown in Fig. 3a was additionally coated with $\mathrm{Cu}$ and embedded in resin. The region limited by the white lines in Fig. 3a is a reaction zone 
which appeared due to interdiffusion between coating and the fibre caused by annealing at $600^{\circ} \mathrm{C}$ for 2 hours. In contrast to Fig. 3a, the image in Fig. $3 \mathrm{~b}$ was taken in a backscatter mode of SEM to get a higher element contrast. Therefore, the $\mathrm{W}$ layer $(Z=74)$ is visible as a white stripe, whereas the $\mathrm{C}(\mathrm{Z}=6)$ and steel $(\mathrm{Fe}, \mathrm{Z}=26)$ areas appear as darker, grey areas. If $\mathrm{W}$ or Fe had interacted with the outer coating of the fibre, the reaction zone would have appeared as a bright white stripe, as it is in Fig. 3a. Thus, the annealing experiment confirms the applicability of the results collected with planar substrates to the fibre case. The $\mathrm{W}$ layer is proven to be an efficient diffusion barrier to suppress the interdiffusion between SCS6 fibre and steel at $750^{\circ} \mathrm{C}$.

\section{Conclusion}

The interdiffusion processes between SCS6 fibres and a steel coating with and without application of a diffusion barrier have been investigated. Strong diffusion of $\mathrm{C}$ into steel is observed. The application of $\mathrm{Cr}$ and Re barriers is not sufficient to suppress the $\mathrm{C}$ diffusion. In contrast, the $\mathrm{W}$ interlayer and $\mathrm{Re} / \mathrm{W}$ multilayer barriers proved to be much more efficient diffusion barriers. The applicability of the results collected for the planar samples have been confirmed by coating of an SCS6 fibre with steel and a W diffusion barrier. No interaction is observed in the latter case between the layers and the fibre. 


\section{References}

1. S.J. Zinkle, N.M. Ghoniem, Fusion Eng. Des. $51-52$ (2000) 55

2. R. Andreani, E. Diegele, R. Laesser, B. van der Schaaf, J. Nucl. Mater. 329-333 (2004) 20

3. H. Bolt, V. Barabash, W. Krauss, J. Linke, R. Neu, S. Suzuki, N. Yoshida, ASDEX Upgrade Team, J. Nucl. Mater. 329-333 (2004) 66

4. R. Lindau, A. Möslang, M. Schirra, P. Schlossmacher, M. Klimenkov, J. Nucl. Mater. $307-311(2002) 769$

5. S. Jitsukawa, A. Kimura, A. Kohyama, R.L. Klueh, A.A. Tavassoli, B. van der Schaaf, G.R. Odette, J.W. Rensman, M. Victoria, C. Petersen, J. Nucl. Mater. 329-333 (2004) 39

6. J.H. You, H. Bolt, J Nucl. Mater. 305 (2002) 14

7. P. Mogilevsky, A. Werner, H.J. Dudek, Mater. Sci. Eng. A242 (1998) 235

8. F. Della Martina, B. Coutand, Y. Le Petitcorps, J.M. Quenisset, Composite Sci. Technol. $53(1995) 65$.

9. M. Mayer, Nucl. Instr. and Meth. B194 (2002) 177

10. D.V. Shtansky, G. Inden, Acta Metal., 45 (1997) No.7 2861 


\section{Figure captions}

Fig. 1 SEM images of the planar SiC samples with W diffusion barrier: a) original sample; b) sample annealed at $750^{\circ} \mathrm{C}$ for 2 hours.

Fig. 2 Mean concentration of $\mathrm{C}$ in the steel layer after annealing at $750^{\circ} \mathrm{C}$ for 2 hours.

Fig. 3 SEM images of cross-section of the SCS6 fibres coated with: a) steel without interlayer, annealed at $600^{\circ} \mathrm{C}$ for 2 hours, b) W and steel layers, annealed at $750^{\circ} \mathrm{C}$ for 2 hours. 
2 columns
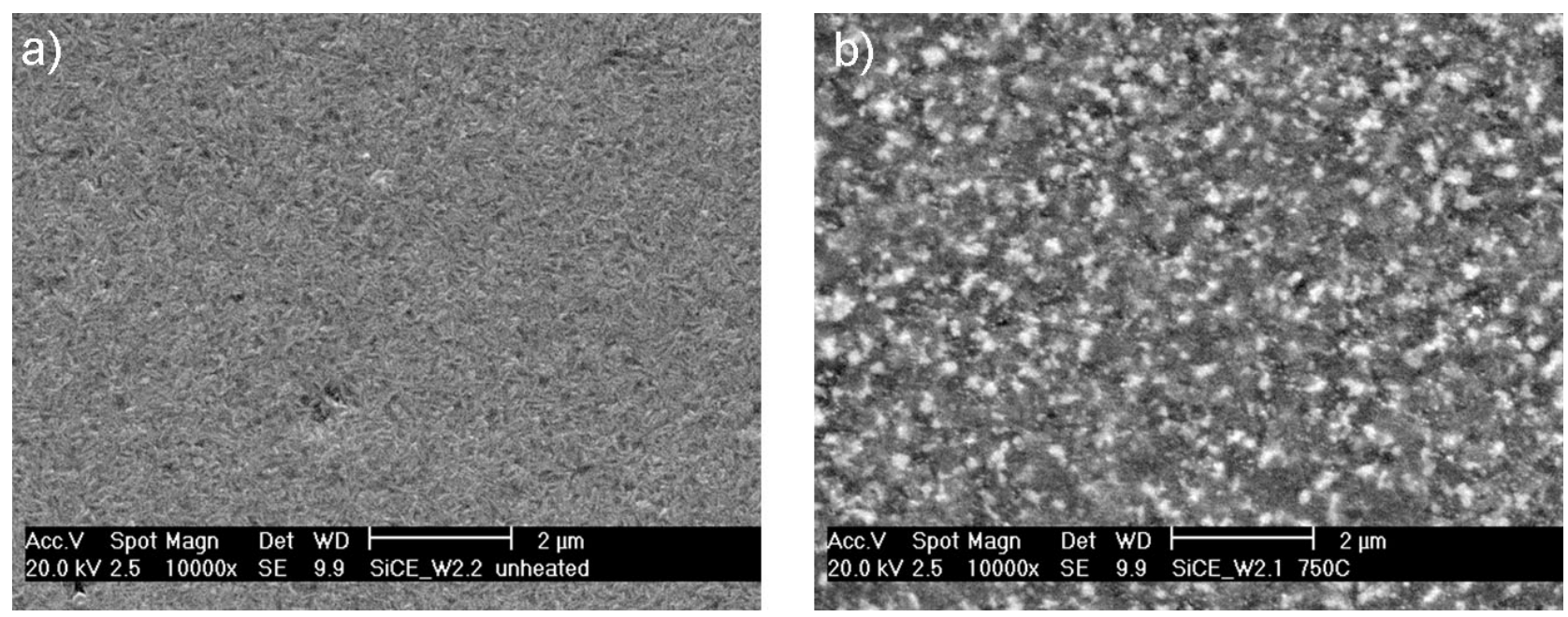

Fig. 1 SEM images of the planar SiC samples with $\mathrm{W}$ diffusion barrier: a) original sample; b) sample annealed at $750^{\circ} \mathrm{C}$ for 2 hours. 
C diffusion into EUROFER with and without barrier, annealing at $750^{\circ} \mathrm{C}$ for $2 \mathrm{~h}$

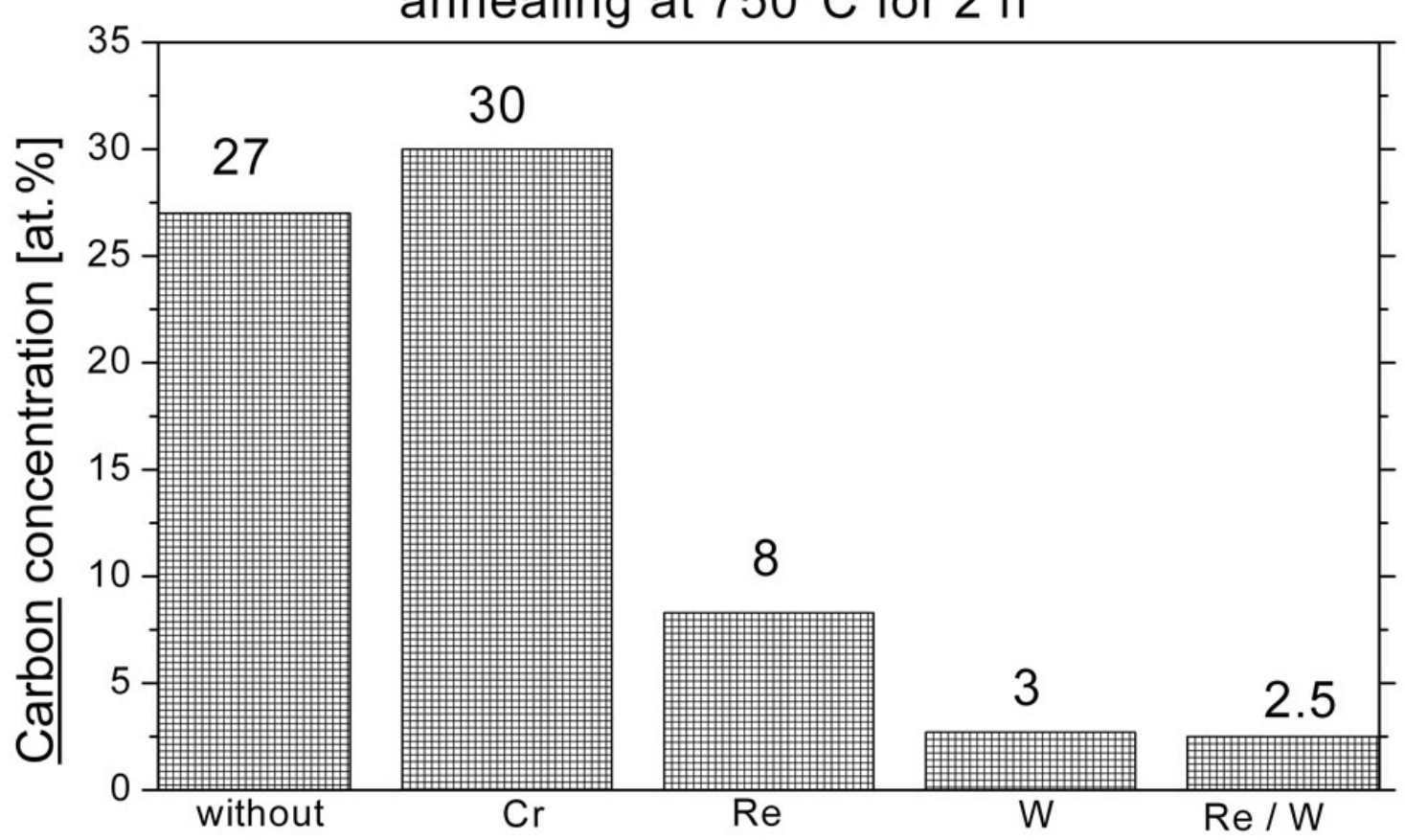

Fig. 2 Mean concentration of $\mathrm{C}$ in the steel layer after annealing at $750^{\circ} \mathrm{C}$ for 2 hours. 

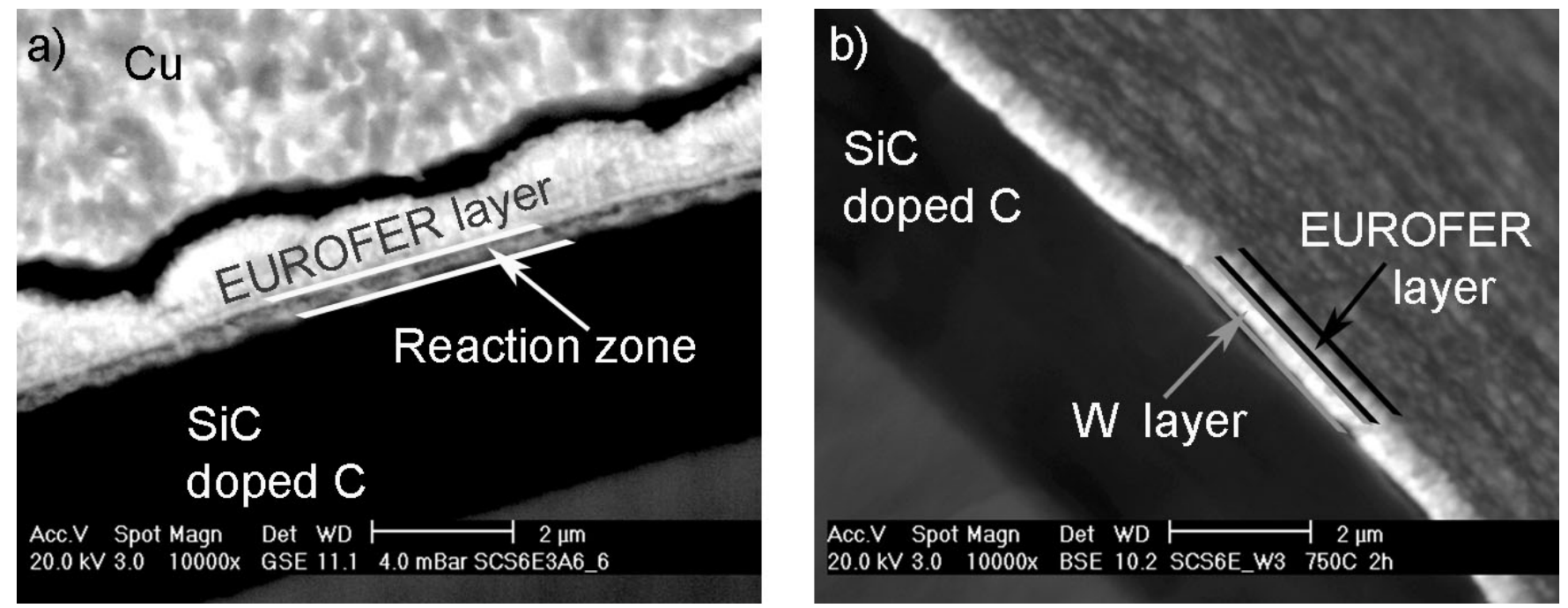

Fig. 3 SEM images of cross-section of the SCS6 fibres coated with: a) steel without interlayer, annealed at $600^{\circ} \mathrm{C}$ for 2 hours, b) W and steel layers, annealed at $750^{\circ} \mathrm{C}$ for 2 hours. 